\title{
The correlation of age of onset with CTG trinucleotide repeat amplification in myotonic dystrophy
}

Alasdair Hunter, Catherine Tsilfidis, Gabrielle Mettler, Pierre Jacob, Mani Mahadevan, Linda Surh, Robert Korneluk

\begin{abstract}
The gene for myotonic dystrophy (DM) has recently been isolated and amplification of an unstable CTG trinucleotide repeat, located within the DM gene, has been identified in virtually all patients studied to date. A high proportion of DM families who are studied show a progressively earlier age of onset with succeeding generations and, in the few pedigrees reported so far, an increasing degree of amplification of the CTG repeat has been noted to parallel this trend. It has been implicit in several of the original reports on the nature of the changes in the DM gene that knowledge of CTG amplification status at the DM locus of a person will provide useful information concerning prognosis. However, no studies of genotype-phenotype correlation have been reported and there are no specific data on which to base such counsel. In this paper we report the correlation between the degree of CTG amplification and age of onset in 109 DM gene carriers from 17 families. Included are parent-child and sib-sib comparisons which provide a framework in which to incorporate DNA diagnostic studies when counselling subjects and families at risk for DM.
\end{abstract}

(f Med Genet 1992;29:774-9)

Myotonic dystrophy (DM) is the most prelevant form of muscular dystrophy and is estimated to affect 1 in 8000 persons worldwide. Furthermore, it is present in up to $1 / 475$ inhabitants of the Saguenay-Lac St Jean region of Quebec, ${ }^{1}$ and maintains a high rate in the general French Canadian population. Recently variable expansion of an unstable DNA fragment at a polymorphic site on chromosome $19 \mathrm{q} 13.3$

Division of Genetics, Children's Hospital of Eastern Ontario, 401 Smyth Road, Ottawa, Ontario K1H 8L1, Canada.

A G W Hunter

C Tsilfidis

G Mettler

P Jacob

M Mahadevan

L Surh

R G Korneluk

Correspondence to Dr Hunter.

Received 8 June 1992. Revised version accepted 30 June 1992. has been reported in patients with DM..$^{2-4}$ The unstable site has been identified as a CTG trinucleotide repeat found within the $3^{\prime}$ untranslated region of a gene showing homo$\operatorname{logy}$ to the serine-threonine specific family of protein kinases. ${ }^{5-7}$ The repeat is highly polymorphic in the general population where it occurs with a range of between five and 38 repeats. Almost all affected subjects have shown significant amplification of the repeat over that seen in the general population, although two of 98 families in one survey showed no expansion ${ }^{7}$ and merit further study. The number of repeats has been reported to increase with successive generations and the clinical severity/age of onset to correlate with the degree of expansion of the allele. However, no substantive clinical data have been provided to support this contention and authors have tended to simplify the definition of severity into the three broad categories described by Harper $^{8}$ (congenital; late adolescence and early adulthood onset; and middle to old age with cataracts and minimal if any muscle weakness). The age of onset and severity of DM are a continuum. Marked variation between generations is characteristic, and while correlation between sibs is relatively high $(r=0.66),{ }^{9}$ significant differences may be seen between sibs. Differences in allele size between sibs have been reported. ${ }^{3}$ Any means of providing prognosis specific to an individual person is therefore of paramount importance.

The studies published to date suggest but do not prove a correlation between allelic expansion and severity. The specific characteristics of this relationship need to be established before changes in practice in genetic counselling for DM. This is especially so with respect to prenatal diagnosis. Our regional genetic service for Eastern Ontario and Western Quebec has a large French Canadian population and $\mathrm{DM}$ is the most common single gene disorder seen for genetic counselling. We have therefore reassessed the signs and symptoms of affected members of a subset of our DM families to explore the relationship of a subject's gene expansion status to disease prognosis. Although detailed clinical data were obtained for all patients in this report, the analysis is simplified to an analysis by age of onset, which correlates well with ultimate disease severity. ${ }^{8}$

\section{Materials and methods}

DNA ANALYSIS

Genomic DNA was extracted from either peripheral blood samples or lymphoblast cultures using modifications of the methods of Madisen et al ${ }^{9}$ or Miller et al. ${ }^{10}$ The DNA ( 3 to $5 \mu \mathrm{g}$ ) was digested with EcoRI (New England Biolabs), electrophoresed on $0.8 \%$ agarose gels, Southern transferred onto nylon membrane (Hybond $^{\mathrm{T} m, A m e r s h a m}$, and probed overnight with a radiolabelled $2 \cdot 2 \mathrm{~kb} B a m \mathrm{HI} / E c o \mathrm{RI}$ subclone of probe pGB2.6. ${ }^{7}$ This genomic probe detects the CTG trinucleotide variable length polymorphism associated with DM. Membranes were washed in $0.2 \times$ saline sodium citrate (SSC), $0 \cdot 1 \%$ sodium dodecyl sulphate (SDS) 
at $60^{\circ} \mathrm{C}$ and exposed to Kodak XAR film for one to four days at $-80^{\circ} \mathrm{C}$.

CTG trinucleotide repeat length was classified using the following scale: E0, no visible expansion on Southern blot but proven to be a DM gene carrier by linkage analysis; E1, expansion of $0<1.5$ kilobase pairs ( $\mathrm{kb}$ ); E2, expansion of $1.5<3.0 \mathrm{~kb} ; \mathrm{E} 3$, expansion of $3.0<4.5 \mathrm{~kb}$; E4, expansion $\geqslant 4.5 \mathrm{~kb}$. Broad classification categories were used owing to the high degree of somatic heterogeneity associated with the CTG repeat, whose complex pattern does not readily lend itself to specific analysis and categorisation.

\section{PCR BASED ANALYSIS}

Polymerase chain reaction (PCR) amplification of the CTG repeat provides a more accurate assessment of its size. It detects expansion not visible on Southern blots of E0 subjects and was used to rank the size of expansion between family members who had the same E0 to E2 class. Genomic DNA ( $1 \mu \mathrm{g})$ was PCR amplified with primers 406 and $409^{7}$ using a standard protocol of 30 cycles at $94^{\circ} \mathrm{C}$ for one minute, $60^{\circ} \mathrm{C}$ for one minute, and $72^{\circ} \mathrm{C}$ for 1.5 minutes. Amplified DNA was electrophoresed on $1 \%$ agarose gels, vacuum blotted onto nylon membrane (Hybond ${ }^{\mathrm{Tm}, \mathrm{Amersham}}$ ), and probed with a labelled (CTG) ${ }_{10}$ oligonucleotide. Membranes were washed in $6 \times \mathrm{SSC}, 0 \cdot 1 \%$

Relationship of allele size to age of onset

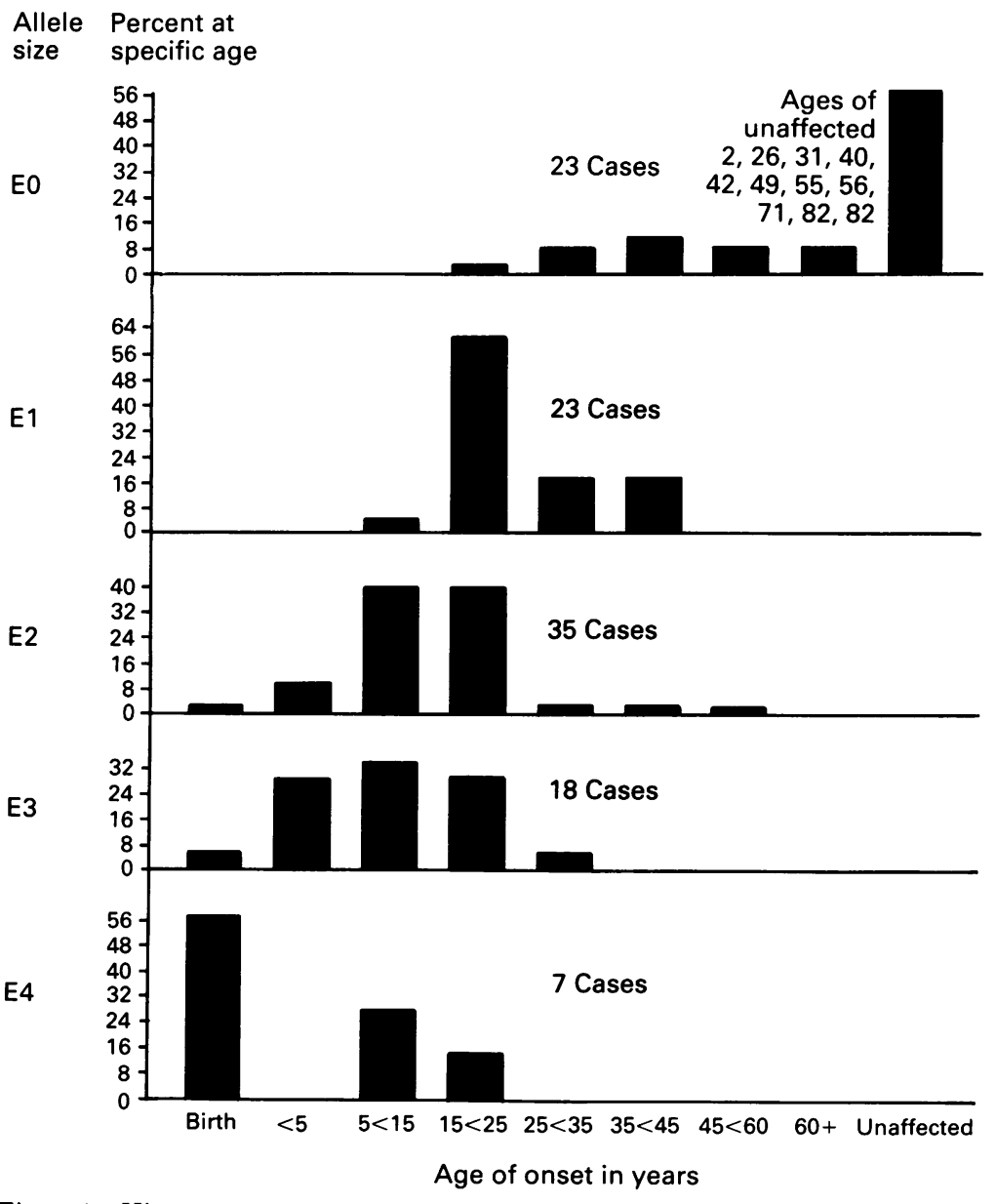

Figure 1 Histograms comparing age of onset for each major size category of allele.
SDS at $45^{\circ} \mathrm{C}$ and exposed to Kodak XAR film for 1.0 to 2.5 hours at $-80^{\circ} \mathrm{C}$.

\section{FAMILIES}

Fifteen families who had been genotyped for the DM mutation, lived close by, and were of sufficient size were chosen from the over 120 kindreds whose DNA had been referred to our laboratory. Two additional small families presented during the six week study period and were included. The clinical investigators were aware who were DM positive by linkage analysis but they were blinded to the degree of allele expansion until after the study.

A total of 109 DNA proven positive DM subjects was evaluated using a standard history and examination protocol. Most families were seen as a group, usually at one member's house but occasionally in the genetic clinic. This turned out to have a significant advantage in terms of corroborating data and examining family photographs. In one family, telephone interviews, medical records, and photographs were used for some members. All physical examinations were carried out by one or two clinicians ( $\mathrm{AH}, \mathrm{PJ})$; interviews were carried out by $\mathrm{AH}$ or GM. Ophthalmological assessments were carried out using a portable slit lamp ( $\mathrm{AH})$, and in case of doubt patients were referred to a genetic-ophthalmologist for assessment.

Persons were categorised by age of onset as follows: congenital, postnatal and $<5$ years, 5 to $<15$ years, 15 to $<25$ years, 25 to $<35$ years, 35 to $<45$ years, 45 to $<60$ years, above 60 years, and as clinically unaffected at the time of study. Although arbitrary, these divisions were chosen because they seemed to follow the milestones patients used (for example, late teens, early 30s). Muscle weakness or myotonia or both as first noted by the patient defined the onset of the disease. Every attempt was made to correlate this timing by noting the results of previous medical examinations, by examining photographs, and by confirming information with other family members. Other symptoms, such as school difficulty, poor performance in sports, constipation, excessive somnolence, and cataracts in someone over 50 , were recorded but were not considered specific enough on retrospective evaluation to mark onset of DM.

These broad age categories were used to search for correlations between allele expansion and age of onset across the total patient group, as well as between parent-sib and sibsib sets within individual families. In addition the relationship between school performance and allele size was studied.

\section{Results}

RELATIONSHIP OF AGE OF ONSET TO ALLELE SIZE IN TOTAL PATIENT GROUP

The ages of onset for each allele size category are presented in fig 1 . Despite a significant overlap between age groups, a trend to earlier age of onset with increasing allele size is readily apparent. This trend is most distinct in the 
E0 category; only one of 23 patients had onset of clinical symptoms before the age of 25 years, and 10 of the 11 clinically unaffected subjects were older than 25 years at the time of study. The one woman with earlier onset was aged 26 years and had clinical myotonia, hand and facial weakness, slurred articulation, and a positive slit lamp examination. Her EMG was equivocal. The CTG trinucleotide amplification within this E0 group of patients, as determined by PCR assay, ranged from 120 to 400 DNA base pairs (bp); no correlation between age of onset and allelic expansion was noted within the group (data not shown).

The majority of E1 patients had onset between the age of 15 and $<25$ years. In the E2 class, $40 \%(14 / 35)$ had onset between 5 and $<15$ years. There was a broad range of age of onset among the E3 class, but an important $28 \%(5 / 18)$ had onset under the age of 5 years. Congenital myotonia ${ }^{11}$ occurred in 3\% $(1 / 35)$ of E2 and $5.6 \%(1 / 18)$ of E3 patients, but similar proportions of subjects in these same classes did not show signs of DM until they were over 25 years.

There were only seven patients with class E4 alleles and it is likely that their absence in the onset $<5$ years is a reflection of the small sample size. Four of the seven were congenital cases. The one patient with onset between 15 and $<25$ was examined at the age of 54 years. $\mathrm{He}$ had been intellectually slow at school but had played some sports. At 54 years he was severely affected but could still walk. He had suffered from a symptomatic cardiomyopathy since his early $40 \mathrm{~s}$.

These data provide a median and range of age of onset for each allele class.

\section{PARENT-CHILD COMPARISONS}

Parents and their children were compared to see if intrafamilial genotype/phenotype correlations may be superior to those observed in the general DM population, and thus provide a more specific means of predicting age of onset and hence severity. Each of the 55 parentchild pairs was compared for allele size and age of onset (table 1). In all 38 pairs where the child showed allele expansion beyond the class seen in the affected parent there was an earlier onset in the child. Furthermore, in 33 of these 37 pairs the child was two or more age groupings earlier in onset than the parent ( 24 cases) or the parent was asymptomatic at the time of study (nine cases).

In 15 of 17 cases where the parent and child were in the same allele size class the child had earlier onset than the parent. In 10 of these 15

Table 1 Relationship of allele size to age of onset in parent-child combinations (numbers are the total parent-child sets/group).

\begin{tabular}{|c|c|c|c|c|c|}
\hline \multicolumn{2}{|c|}{$\begin{array}{l}\text { Child's allele larger than parent } \\
\text { on Southern blot }\end{array}$} & \multicolumn{4}{|c|}{$\begin{array}{l}\text { Child's allele same size as } \\
\text { parent on Southern blot }\end{array}$} \\
\hline $\begin{array}{l}\text { Parent and child } \\
\text { in same age class }\end{array}$ & $\begin{array}{l}\text { Child earlier } \\
\text { onset }\end{array}$ & $\begin{array}{l}\text { Paren } \\
\text { in sam }\end{array}$ & $\begin{array}{l}\text { child } \\
\text { e class }\end{array}$ & Chil & lier \\
\hline 0 & 38 & $\begin{array}{l}\text { PCR }>\text { in } \\
\text { child } \\
1\end{array}$ & $\begin{array}{c}\mathrm{PCR}=\text { in } \\
\text { pair } \\
1\end{array}$ & $\begin{array}{l}P C R>\text { in } \\
\text { child } \\
10\end{array}$ & $\begin{array}{l}\mathrm{PCR}=\text { in } \\
\text { pair } \\
5\end{array}$ \\
\hline
\end{tabular}

parent-child pairs the allele, although within the same category, was seen to have undergone clear cut expansion in the child when examined with PCR (fig 2). Of these 10 pairs, the child was two or more age groupings earlier in onset than the parent in six cases and the parent was asymptomatic at the time of study in two cases. In five of these 15 parent-child pairs both subjects had the same allele size even when examined with PCR. In four pairs the subject's age of onset differed by a single category. In the final pair the mother had onset between 35 and $<45$ years and the child between 15 and $<25$ years and a 180 bp (E0) fragment was transmitted apparently unchanged.

In the one case where parent and child were in the same age of onset group and the PCR showed further expansion in the child, the child had onset of DM between the age of 1 and 2 years and the mother at about the age of 5 years.

GENDER OF PARENT AND AGE OF ONSET

The mother was the gene carrier in 35 cases and the father in 17 cases, when an earlier onset occurred in the child $\left(\chi^{2}=6 \cdot 2\right.$, $\mathrm{p}<0.025)$. Furthermore, in nine of 11 cases where the parent was clinically unaffected at the time of study, it was the father who transmitted the DM gene, which, given the observed sex ratio of transmitting parents, gives a $\chi^{2}$ of 10.4 (Yates's correction, $\mathrm{p}<0.005)$. In contrast, six of seven children

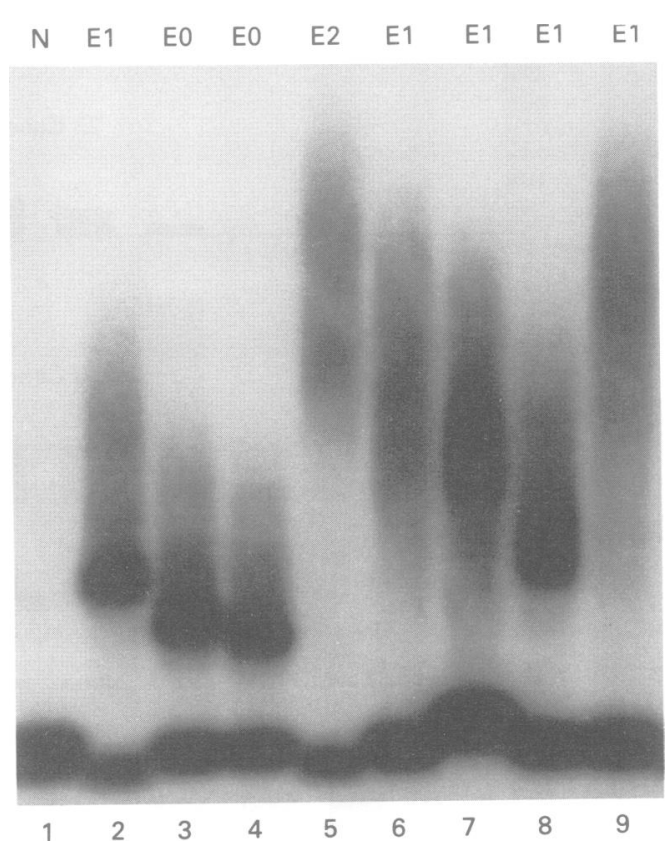

Figure 2 The CTG trinucleotide repeat from a single family, PCR amplified and probed with the (CTG) 10 oligonucleotide. $E$ values above the figure represent the CTG expansion seen on EcoRI digested Southern transferred DNA probed with pGB2.6. PCR correlates
trath well with Southern data. In addition PCR often allows differentiation between subjects found with the same ' $E$ ' category. Lane 1 contains a non-DM subject. All other lanes contain DM subjects. Although lanes 2, 6, 7, 8, and 9 all contain $E 1$ expanded patients $(0$ to $<1.5 \mathrm{~kb})$, and 9 all contain E1 expanded patients $(0$ to $21.5 \mathrm{~kb}$, less expanded than lanes 6 and 7. Lane 9 shows the greatest degree of expansion. 
Table 2 Sib to sib correlation for age of onset and allele size.

\begin{tabular}{|c|c|c|c|c|c|c|}
\hline \multicolumn{4}{|c|}{ Same allele category } & \multicolumn{3}{|c|}{ Different allele category } \\
\hline \multirow[t]{2}{*}{$\begin{array}{l}\text { Same } \\
\text { severity }\end{array}$} & \multicolumn{3}{|c|}{$\begin{array}{l}\text { Different } \\
\text { severity }\end{array}$} & \multicolumn{2}{|c|}{$\begin{array}{l}\text { Different severity, } \\
\text { larger allele in: }\end{array}$} & \multirow[t]{2}{*}{$\begin{array}{l}\text { Same } \\
\text { severity }\end{array}$} \\
\hline & $\begin{array}{l}\text { PCR }>\text { in } \\
\text { early } \\
\text { onset sib }\end{array}$ & $\begin{array}{c}\text { PCR }= \\
\text { in both } \\
\text { sibs }\end{array}$ & $\begin{array}{l}\mathrm{PCR}<\text { in } \\
\text { early } \\
\text { onset sib }\end{array}$ & $\begin{array}{c}\text { Early } \\
\text { onset } \\
\text { sib }\end{array}$ & $\begin{array}{c}\text { Later } \\
\text { onset } \\
\text { sib }\end{array}$ & \\
\hline 15 & 3 & 7 & 2 & 11 & 1 & 6 \\
\hline
\end{tabular}

with onset from birth to $<5$ years received the gene from their mother. This observation does not reach statistical significance given the small numbers and overall preponderance of transmitting females.

SIB-SIB CORRELATIONS FOR AGE OF ONSET Pairs of sibs were examined for correlation between age of onset and allele category as defined by Southern blotting. When two sibs had the same class of allele expansion they were compared for relative size using PCR

Educational histories

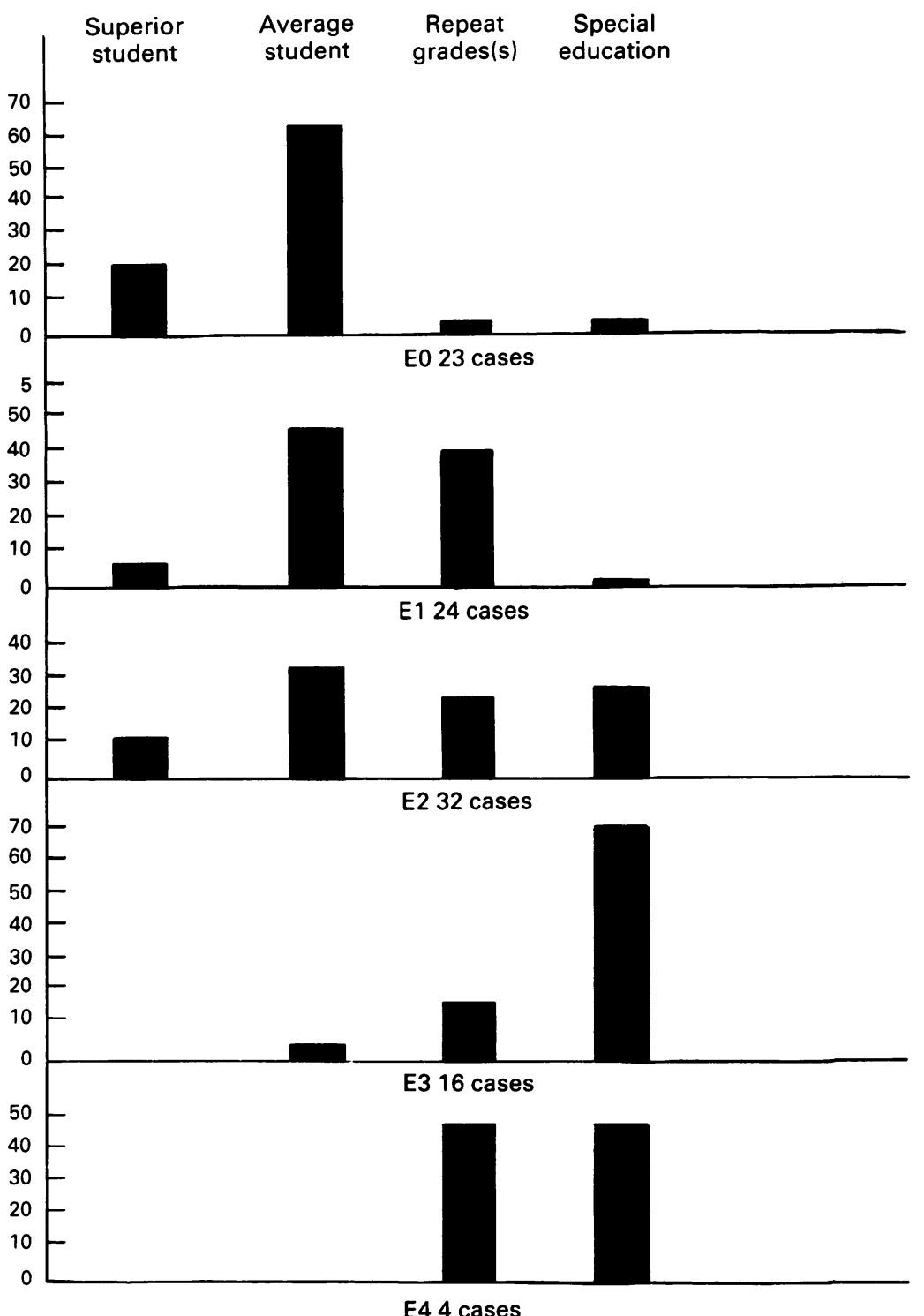

Figure 3 Histograms comparing school performance for each major category of allele. (table 2). Twenty-nine of 45 sib pairs were either matched for age of onset and allele class, or the sib with earlier onset had greater expansion of the allele (Southern blot or PCR). In only one of the seven pairs where sibs had apparently similar alleles but an earlier age of onset in one sib was the difference more than one age category. In that pair, who both had E4 alleles, one of the sibs was congenital. She spent the first month in hospital because of breathing difficulties and did not walk until 5 years of age. Her sister first noted myotonia at the age of 10 years and at that time her mother noted her hands and wrists were weak. When examined at 32 and 34 years respectively, the former was retarded with the facial appearance of congenital myotonia and could not walk without support, while the latter was of normal intelligence, married, and remained relatively independent, although significantly handicapped. The more severely affected sib did show greater expansion on the Southern blots although both were $>4.5 \mathrm{~kb}$. Birth order did not appear to be related to differences in allele expansion or age of onset between sibs.

The six sib pairs who differed in allele class but had the same age of onset differed by a single class. The one pair where the age of onset was earlier in the sib with the smaller allele involved a E0/E1 combination with a very large $\mathrm{E} 0$ and onset 25 to $<35$ years and 35 to $<45$ years respectively.

\section{SCHOOL PERFORMANCE}

Fig 3 compares school performance for the different allele sizes. Patients and their families were simply asked whether the person was considered a superior or average student and whether they had repeated a grade(s) or had required a special education or vocational programme. The distribution of school performance in the E0 class is as would be expected from the general population. However, over $40 \%$ of subjects in the E1 category had failed at least one grade, while failures or the need for special/vocational education occurred in most persons with $\geqslant E 2$ expansion. The numbers in the E4 category are too small to generalise and indeed we have since seen an adult patient with E4 expansion and normal school performance.

\section{Discussion}

We have observed a clear trend to earlier age of onset (and therefore increasing DM severity) with increasing allele size. This trend to greater severity with increasing expansion was also apparent when school performance was examined. While these population data provide general guidelines for genetic counselling, the ranges are broad with significant overlap and the intra-allele class variation in age of onset is, at times, highly clinically relevant. For example, not all subjects with E4 allele size have congenital DM, while some patients with E2 or E3 size alleles are affected with this form of DM. Using PCR to distinguish between alleles within a class does not appear to help in refining the prediction as to age of onset. It 
may be that the degree of somatic heterogeneity seen is representative of the tissue examined (in this case lymphoblasts) or the age of the subject. If this is the case, the studies on CTG expansion in different tissues or at different ages in the same subject may help to define these categories better and account for the degree of overlap that appears between them. It should also be kept in mind that two families have been reported where $D M$ is present but where the number of CTG trinucleotide repeats is the same as that seen in the normal population. ${ }^{7}$ Other sorts of gene change are being sought in these families.

However, in most cases of DM counselling, additional members of the family are available for study and a potentially affected subject can be compared with an affected parent or sib or both. If a child has an allele class increase as compared with the parent it is almost certain that there will be an earlier age of onset. The child had onset more than one age class earlier in 33 of 38 such pairs. Inaccuracy of historical recall or the arbitrary division of the age categories are unlikely to explain these findings. Furthermore, a clear increase of size within an allele category, as identified by PCR, also correlated well with earlier onset in the child. Most of the exceptions differed by only one age category and may not have reflected true biological differences. One family was truly unusual in showing increasingly earlier onset but an apparently unchanged $180 \mathrm{bp}$ allele.

Most sibs with similar allele sizes showed comparable ages of onset and sibs with larger alleles showed earlier onset. The exceptions where sibs with the same allele class had a different age of onset were again most often limited to a single age group difference. The cases where sibs had similar age of onset but differed by allele size did so by a single allele class. Some of these cases may have related to problems obtaining reliable historical data.

The observation that it was more often a father who was an unaffected DM carrier is interesting in light of the fact that there does not appear to be any difference in the magnitude of expansion that occurs with paternal versus maternal transmission of the gene. ${ }^{11}$ This post hoc finding should be addressed in a fresh data set. Although not statistically significant, the fact that it was affected mothers who gave birth to the children with onset in the first three years of life raises the question as to whether such children represent an extended spectrum of 'congenital' DM, with an implied maternal effect that is independent of CTG repeat size.

Only one of the 55 parent-child pairs was identified where both had the same allele category, PCR analysis, and age of onset. However, a broader population based study is required before it is assumed that the paucity of such pairs reflects the true frequency with which the CTG trinucleotide expands with successive generations. Two instances in these families where the child has received a smaller allele than that of the parent will be the subject of a separate report.
In a cross sectional study of this nature, the ability to pinpoint onset of the illness will clearly be affected by the time that has passed since actual onset and the differing historical skills of the patients. Not uncommonly, a physical examination can be expected to detect signs or elicit symptoms not reported by the patient. However, the families studied provided a good cross section of patients with onset at all ages and different stages of their disease. Overall we were impressed that the 'collaborative' family approach we used provided reliable data.

The necessary clinical approach of dividing the continuum of age of onset and allele size into arbitrary discontinuous categories, together with inevitable errors in historical data, will tend to obscure correlations. Notwithstanding these considerations, we believe these findings provide useful clinical data with which to counsel at risk subjects and families concerning age of DM onset. In the case of the patient where no other family members are available, the size of the expanded allele can be used to provide the most likely age of onset and the possible range. Knowledge of age of onset and of allele size in a parent or sib allows for more specific estimates to be provided. These data and those specifically related to congenital myotonia ${ }^{11}$ may help guide the interpretation of prenatal diagnosis results. However, caution must be used given the range of severity seen with a given allele size, even within families, and the lack of published information concerning the nature of CTG trinucleotide amplification in different fetal tissues.

This study would not have been possible without the unselfish cooperation and assistance from the members of these families and we are truly grateful for their support. We also thank $S$ Leblond, M Foitzik, and D Lahey of the CHEO molecular service laboratory whose linkage studies established the DM status of our patients, Dr Ian MacDonald who provided ophthalmological consultations, and $\mathrm{Dr}$ Alex MacKenzie for his constructive criticism of the manuscript. This work was supported by grants to RK from The Muscular Dystrophy Associations (MDA) of Canada and the United States, the Medical Research Council of Canada, and the Canadian National Centres of Excellence Genetic Disease Network.

1 Bouchard G, Roy R, Declos M, Mathieu J, Kouladjian K. Origin and diffusion of the myotonic dystrophy gene in 1989;116:119-22.

2 Harley HG, Brook JD, Rundle SA, et al. Expansion of an unstable DNA region and phenotypic variation in myotounstable DNA region and phenotypic variat

3 Buxton J, Shelbourne P, Davies J, et al. Detection of an unstable fragment of DNA specific to individuals with unstable fragment of DNA specific to individua
myotonic dystrophy. Nature 1992;355:547-8.

4 Aslanidis C, Jensen G, Amemiya C, et al. Cloning of the essential myotonic dystrophy region and mapping of the putative defect. Nature 1992;355:548-51.

5 Fu YH, Pizzuti A, Fenwick RJ Jr, et al. An unstable triplet repeat in a gene related to myotonic muscular dystrophy. Science 1992;255:1256-8.

6 Brook JD, McCurrah ME, Harley HG, et al. Molecular basis of myotonic dystrophy: expansion of a trinucleotide CTG) repeat at the $3^{\prime}$ end of a transcript encoding a protein kinase family member. Cell 1992;68:799-808.

7 Mahadevan M, Tsilfidis C, Sabourin L, et al. Myotonic dystrophy mutation: an unstable CTG repeat in the $3^{\prime}$ untranslated region of the gene. Science 1992;255:1253-5. 
8 Harper PS. Myotonic dystrophy. 2nd ed. London: Saunders, 1989.

9 Madisen L, Hoar D, Holroyd C, Crisp M, Hodes ME DNA banking: the effects of storage of blood and isolated DNA on the integrity of DNA. Am $f$ Med Genet 1987;27:379-80.

10 Miller SA, Dykes DD, Polesky HF. A simple salting out procedure for extracting DNA from human nucleated cells. Nucleic Acids Res 1988;16:1215.

11 Tsilfidis C, MacKenzie AE, Mettler G, Barcelo J, Korneluk RG. CTG trinucleotide repeat amplification patterns in the myotonic dystrophy (DM) gene: correlation between repeat length and frequency of severe congenital myotonic dystrophy. Nature Genet 1992;1:192-5. 